\title{
Anatomical Variants of Celiac Trunk in Relation to Its Branching: A Preliminary Sub-Saharan Study
}

\author{
Siaka Ben-Aziz Dao1* ${ }^{*}$, Ouattara Boubakar1, Zanga Moussa ${ }^{2}$, Kambou Tiemtore Bénild ${ }^{3}$, \\ Nde Ouedraogo Nina ${ }^{3}$, Ramde Annick ${ }^{1}$, Louazoube P. Gaïba ${ }^{1}$, Zoungrana Robert ${ }^{1}$, \\ Diallo Ousseini' ${ }^{1}$, Cissé Rabiou ${ }^{1}$
}

${ }^{1}$ Centre Hospitalier Universitaire Yalgado Ouedraogo, Ouagadougou, Burkina Faso

${ }^{2}$ Centre Hospitalier Universitaire Charles de Gaulle, Ouagadougou, Burkina Faso

${ }^{3}$ Centre Hospitalier Universitaire de Bogodogo, Ouagadougou, Burkina Faso

Email: ^benazizd@yahoo.fr

How to cite this paper: Dao, S.B.A., Boubakar, O., Moussa, Z., Bénild, K.T., Nina, N.O., Annick, R., Gaïba, L.P., Robert, Z., Ousseini, D. and Rabiou, C. (2019) Anatomical Variants of Celiac Trunk in Relation to Its Branching: A Preliminary Sub-Saharan Study. Open Journal of Radiology, 9, 151-161.

https://doi.org/10.4236/ojrad.2019.92014

Received: March 27, 2019

Accepted: June 25, 2019

Published: June 28, 2019

Copyright $\odot 2019$ by author(s) and Scientific Research Publishing Inc. This work is licensed under the Creative Commons Attribution International License (CC BY 4.0).

http://creativecommons.org/licenses/by/4.0/

\begin{abstract}
Background: Surgical treatment of upper mesocolic organs is improved by preoperative diagnosis of anatomical variants of celiac trunk. According to the literature, these anatomical variants are little known in sub-Saharan Africa. Purpose: To evaluate the prevalence of anatomical variants of celiac trunk in relation to its branching. Materials and methods: This was a cross-sectional study of descriptive type. It retrospectively evaluated 160 abdominal contrast enhanced CT-scan, from patients attending Yalgado OUEDRAOGO teaching hospital, from 1 January 2015 to 30 September 2016. Patients with a history of heavy abdominal surgery were excluded. Images obtained by 64-row CT-scan were analyzed for anatomical variants of the celiac trunk. Results: One hundred and twenty-eight patients $(80 \%)$ had a classic anatomical configuration of celiac trunk, while thirty-two $(20 \%)$ had at least one anatomical variant. Two anatomical variants were found in fifteen patients (9.4\%) while five other patients (3.1\%) had more than two variants. The most frequent anatomical variant was the hepato-splenic bifurcation, found in fourteen patients $(8,8 \%)$. It was followed by common celiac and mesenteric trunk, and then collateral arteries, in particular left hepatic artery and right lower diaphragmatic artery, each with three patients (1.9\%). Conclusion: Anatomical variants related to celiac trunk branching, are as frequent in our study as in the literature. However, the two most common anatomical variants were hepato-splenic bifurcation and common celiac and mesenteric trunk.
\end{abstract}

\section{Keywords}

Celiac Trunk, Anatomical Variant, Hepato-Splenic Bifurcation, 


\section{Introduction}

Celiac trunk is the most important collateral of abdominal aorta with irrigation of vital upper mesocolic organs. It can be affected by thrombosis, extrinsic compression or tumor invasion [1]. Surgical treatment of these pathologies is improved by preoperative diagnosis of anatomical variants (AVs) of celiac trunk. For this purpose CT-angiography is now the gold standard examination, given its good resolution and ease of use [2] [3]. In the absence of an automatic injector, arterial phase of the manually injected abdominal CT-scan also allows celiac trunk study. Since the first description of celiac trunk trifurcation by Haller in 1756 [4], several VAs have been described in nearly half in some populations [1]. More than the topography, the gauge or the path of celiac trunk, VAs focused on the mode of division into terminal branches. The most frequently encountered examples according to a recent study are: stomachic coronary artery of its own origin on the aorta associated with a common hepato-splenic trunk (4.4\%), hepato-mesenteric and gastro-splenic trunks (2.6\%), and common celiac and mesenteric trunk (1.1\%). Despite the increasing availability of contrast-enhanced abdominal CT-scan and the relevance of celiac trunk's AVs exploration, sub-Saharan literature has just a few studies on this topic. The purpose of our study was to evaluate the prevalence of celiac trunk's AVs related to its branching, in our context and to compare it with that of previous studies.

\section{Materials and Method}

This was a single-center retrospective cross-sectional study conducted in the radiology and medical imaging department of Yalgado Ouedraogo University Hospital, Burkina Faso, from January 1, 2015 to September 30, 2016. This was an exhaustive study of all patients who performed an enhanced abdominal CT-scan for several indications. Cases of vascular contusion, pancreatic or hepatic surgery or any other heavy abdominal surgery were not included. Our sample included 160 adult patients. All examinations were conducted on a Siemens Somatom Emotion 64-slices machine. A non-contrast helicoidal acquisition was systematically performed from dome of diaphragms to the pubic symphysis.

Subsequently, for lack of a functional automatic injector 80 to $120 \mathrm{ml}$ of iodinated contrast medium was performed manually. Two senior radiologists and a resident in diagnostic radiology reviewed every CT-scan file. This review was preceded by socio-demographic variable recording and multiplanar reformations, MIP, 3D reconstruction and manual segmentations with SYNGOVIA software.

Data processing and analysis were done using Microsoft Word software, Microsoft Excel version 2013, Epi-Info 3.3.2 software. The Chi-square test was the 
statistical test used for comparisons of variables in search of association. A value of $\mathrm{p}<0.05$ was considered significant

\section{Results}

Our sample consisted of 160 patients, including 93 men and 67 women. The sex-ratio was 1.4 with ages ranging from 18 to 80 years for an average of 45.9 years. The most common age range was between 40 and 50 years as shown in Figure 1. The three most common indications for abdominal CT-scan were tumour extension assessment, assessment of abdominal pain and assessment of abdominal mass as shown in Table 1.

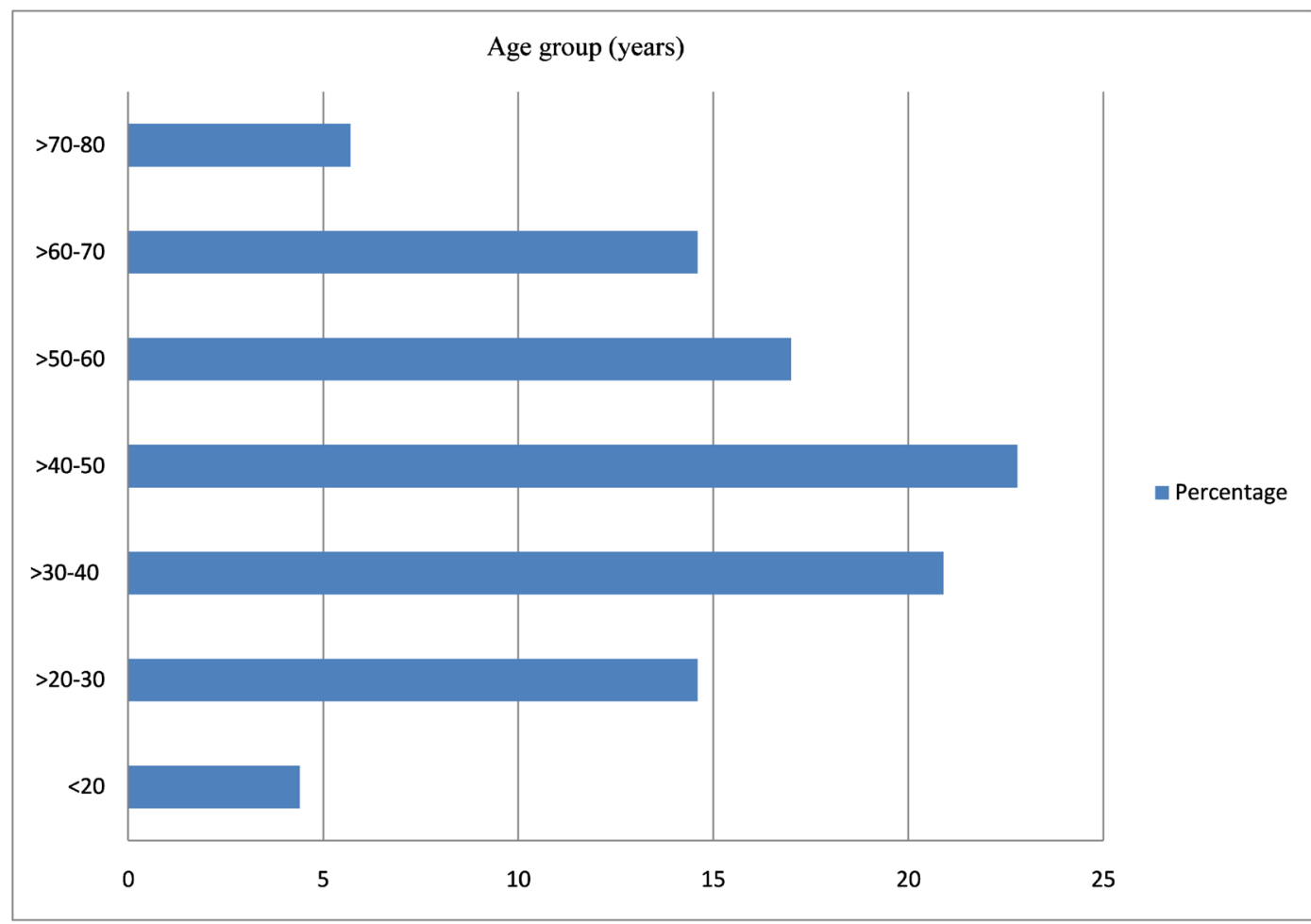

Figure 1. Histogram of patient distribution by age group $(n=160)$.

Table 1. Distribution of patients according to the main indications of exams $(n=160)$.

\begin{tabular}{lcc}
\hline \multicolumn{1}{c}{ Exams indication } & Numbers & Percentage \\
\hline Tumor extension report & 52 & 32.5 \\
Assessment of abdominal pain & 40 & 25 \\
Assessment of an abdominal mass & 36 & 22.5 \\
Assessment of an abdominal trauma & 14 & 8.7 \\
Assessment of an inflammatory pathology & 8 & 5 \\
Edematous-ascites syndrome & 6 & 3.8 \\
Assessment of cervical tuberculosis & 3 & 1.8 \\
Assessment of a recurrent hernia & 1 & 0.7 \\
Total & 160 & 100 \\
\hline
\end{tabular}


One hundred and twenty-eight patients (80\%) had a classical anatomical configuration of celiac trunk, while thirty-two (20\%) had at least one AV. Two AVs were found in 15 patients $(9.4 \%)$ while five other patients $(3.1 \%)$ had more than two AVs. Bifurcation of celiac trunk was the most common type of AV with a total of 14 patients, including hepato-splenic bifurcation (Figure 2), with 12 patients $(7.5 \%)$. The second type of bifurcation found was gastro-splenic with $1.3 \%$ (Figure 3). Collateral arteries were the second most frequent type of AVs with a

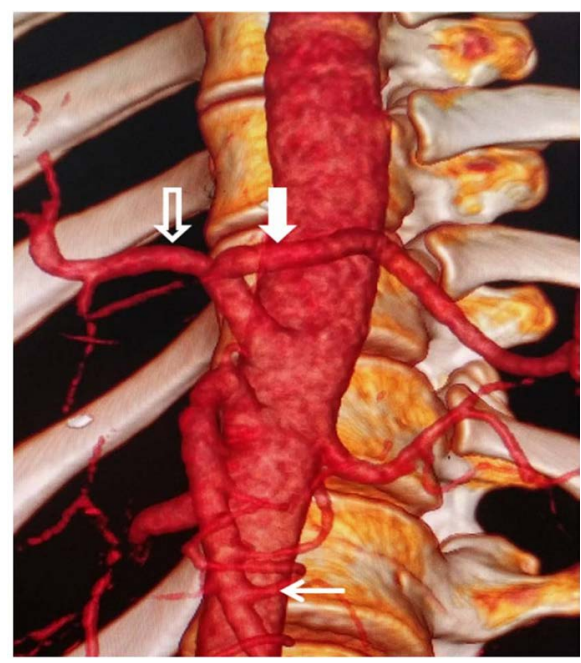

Figure 2. Enhanced abdominal CT-scan showing on 3D reconstruction, a hepato-splenic bifurcation with a common hepatic artery (hollow arrow), a splenic artery (full arrow) and a stomachic coronary artery of inferior mesenteric artery origin (thin arrow).

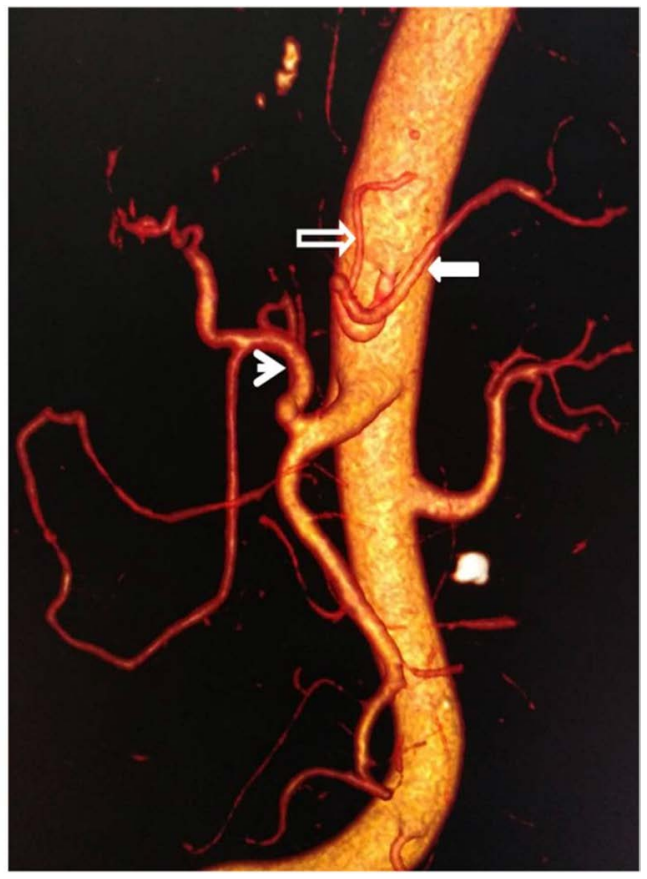

Figure 3. Enhanced abdominal CT-scan showing on 3D reconstruction, a gastro-splenic bifurcation with a stomachic coronary artery (hollow arrow), a splenic artery (full arrow) and a common hepatic artery (arrow head). 
total of 9 patients or 5.6\%. Of these, left hepatic artery (Figure 4) and lower right diaphragmatic artery were the most common with three patients each. Then common celiac and mesenteric trunk followed (Figure 5) with 5 patients.

As for quadrifurcation, there were two types. One had a gastro-duodenal artery (Figure 6) and another had a right hepatic artery associated with a left hepatic artery (Figure 7). One patient among the 3 carriers of a collateral corresponding to a left hepatic artery presented two singularities: a trifurcation made

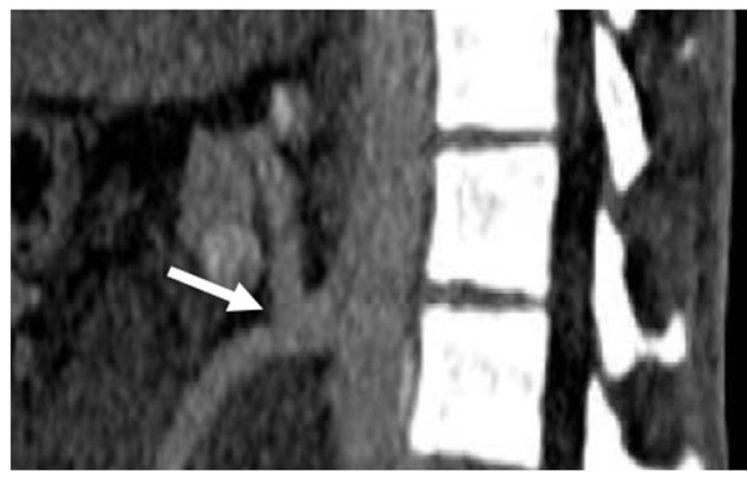

Figure 4. Enhanced abdominal CT-scan showing on 3D reconstruction, a collateral left hepatic artery (arrow head), a splenic artery (thin arrow), a left gastric artery originating from the superior mesenteric artery (hollow arrow) and a right hepatic artery (hatched arrow).

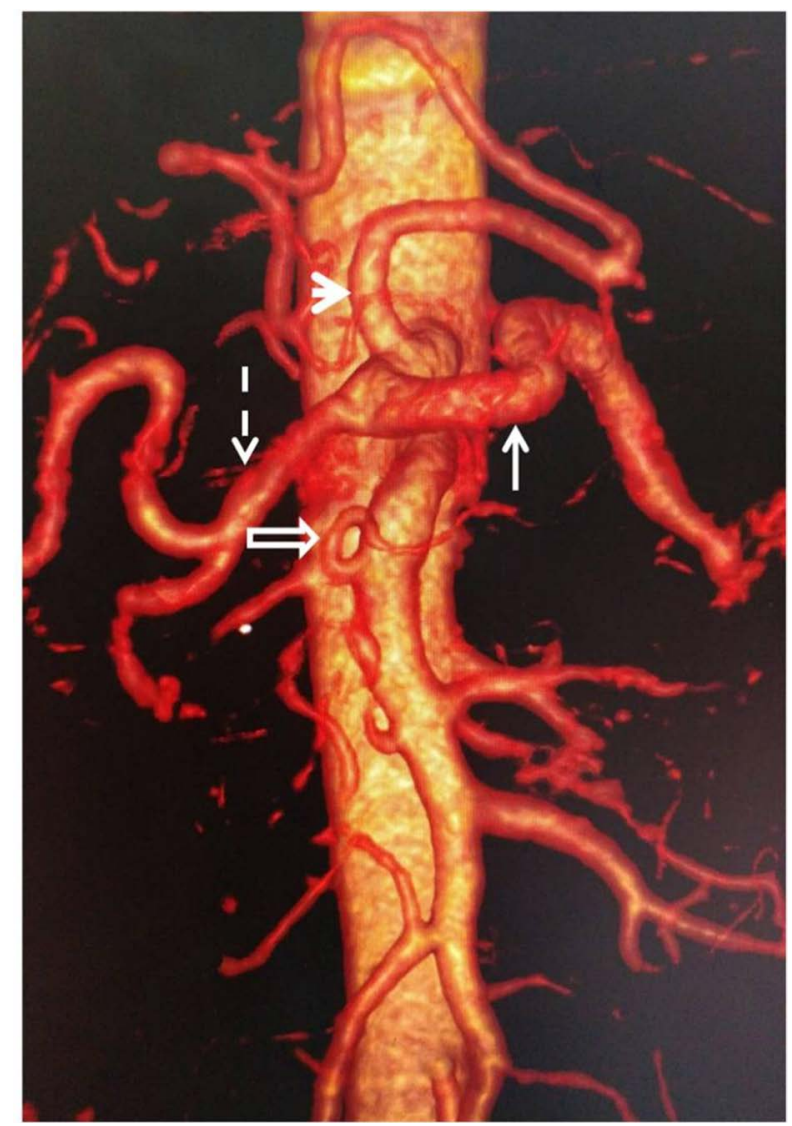

Figure 5. Enhanced abdominal CT-scan showing on 3D reconstruction a common celiac and mesenteric trunk (arrow). 


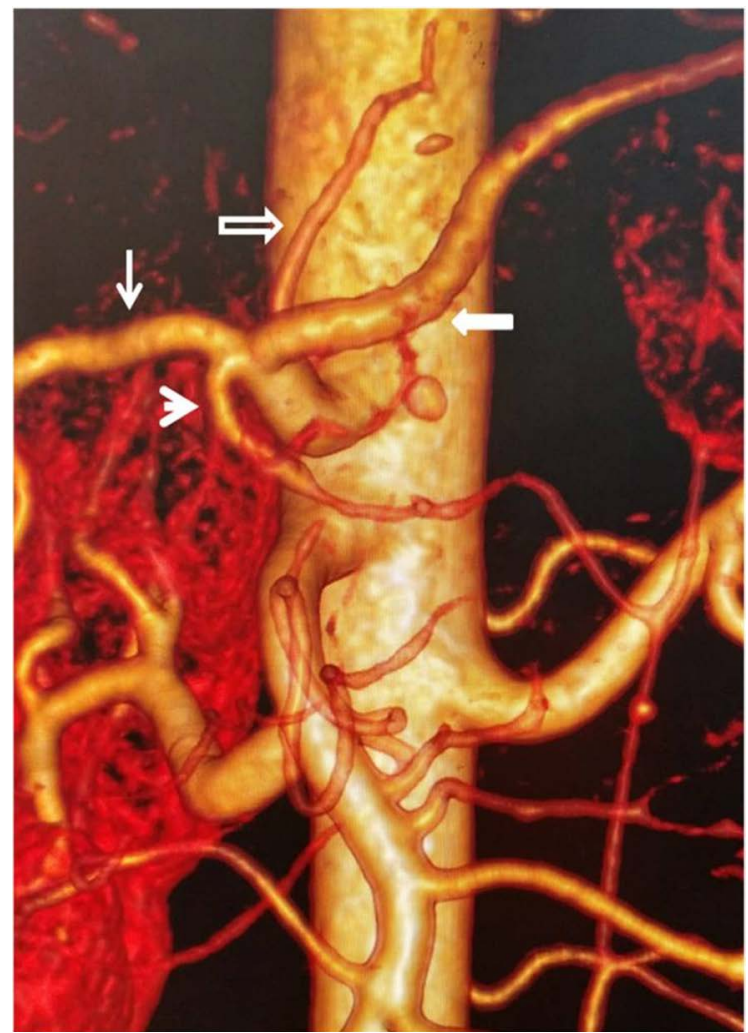

Figure 6. Enhanced abdominal CT-scan showing on 3D reconstruction, a quadrifurcation of celiac trunk, with a common hepatic artery (thin arrow), a stomachic coronary artery (hollow arrow), a splenic artery (thick arrow) and a gastro-duodenal artery (arrow head).

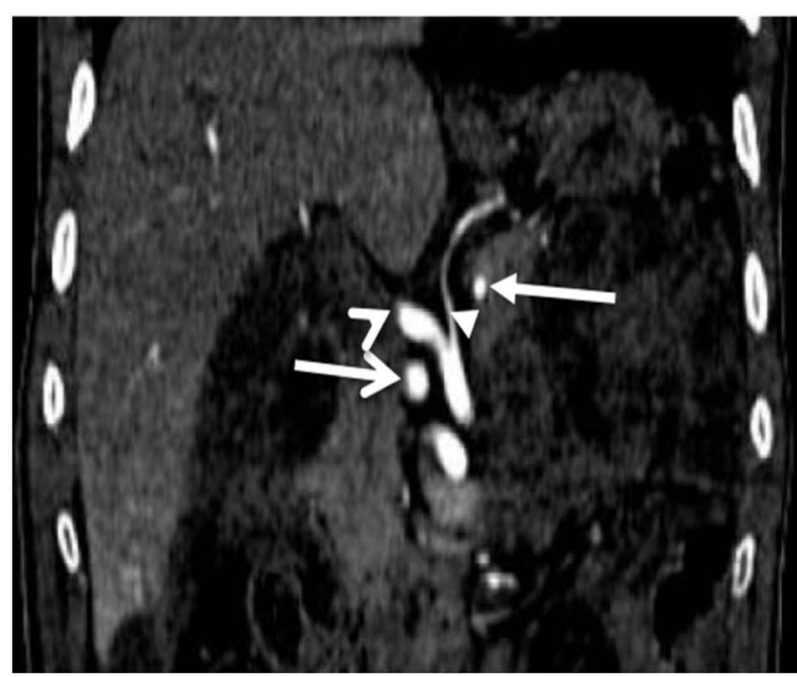

Figure 7. MIP image of enhanced abdominal CT-scan, in frontal section showing a quadrifurcation of celiac trunk, with a right hepatic artery (short arrow), a left hepatic artery (“delta wing”), a stomachic coronary artery (arrow head) and a splenic artery (full arrow).

of two right hepatic arteries and the splenic artery (Figure 8), a "pseudo-arc" of Buhler, stretched between the celiac trunk and the inferior mesenteric artery (Figure 9). Table 2 summarizes all the AVs encountered with their frequencies. 


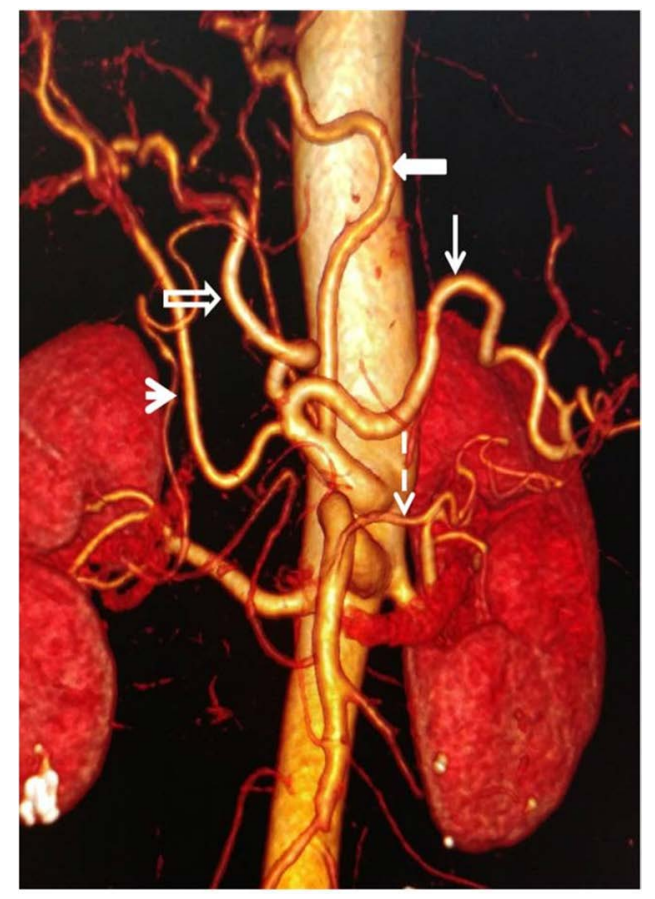

Figure 8. Enhanced abdominal CT-scan on 3D reconstruction showing two right hepatic arteries (arrow head and hollow arrow), a left hepatic artery of collateral disposition (thick arrow), a splenic artery (thin arrow) and a gastric artery originating from superior mesenteric artery (hatched arrow).

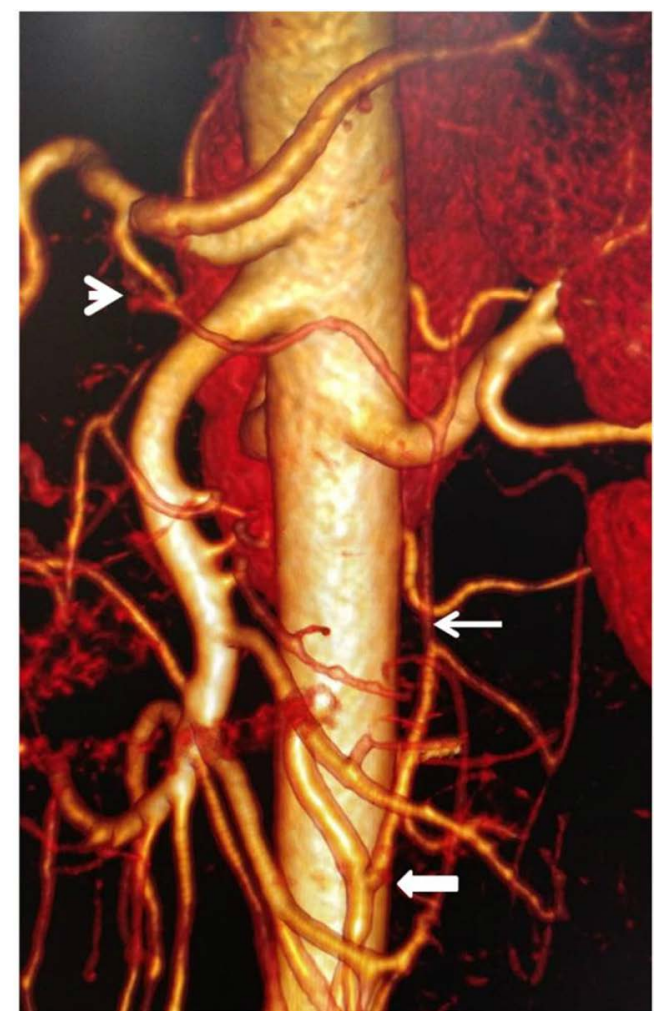

Figure 9. Enhanced abdominal CT-scan on 3D reconstruction showing a "pseudo-arch" of Buhler indicated by a thin arrow whose proximal end is celiac (arrow head) and the distal end is inferior mesenteric (thick arrow). 
Table 2. Distribution of patients according to the mode of division of celiac trunk ( $\mathrm{n}=$ $160)$.

\begin{tabular}{lcc}
\hline Celiac trunk type of branching & Effectif (n) & Percentage (\%) \\
\hline Trifurcation & 128 & $\mathbf{8 0}$ \\
Hepato-splenic bifurcation & 12 & 7.5 \\
Gastro-splenic bifurcation & 2 & 1.3 \\
Quadrifurcation GDA & 1 & 0.6 \\
Quadrifurcation RHA/LHA & 1 & 0.6 \\
Celio-mesenteric trunk & 5 & 3.1 \\
Collateral right IDA & 3 & 1.9 \\
Collateral left IDA & 1 & 0.6 \\
Collateral single IDA & 1 & 0.6 \\
Collateral left hepatic artery & 3 & 1.9 \\
Collateral right hepatic artery & 1 & 0.6 \\
No celiac trunk & 2 & 1.3 \\
Total & 160 & 100.0 \\
\hline
\end{tabular}

Captions: GDA: gastro-duodenal artery; RHA/LHA: right hepatic artery/left hepatic artery; IDA: inferior diaphragmatic artery.

\section{Discussion}

Origin of AVs of celiac trunk is related according to literature to embryogenesis. They result from persistence or abnormal regression of anastomoses between primitive arterial arches.

Few African studies have been reported on AVs of celiac trunk. To the best of our knowledge, only four studies exist, and whole of them on anatomical dissection. The oldest one is from 2007 and comes from Kenya [5]. The next two other studies come from Nigeria and Tanzania [6] [7]. But only a Kenyan publication addressed the prevalence of AVs of celiac trunk in sub-Saharan Africa, hence the merit of our study.

This study presents some shortcomings. Firstly, the size of our sample was modest. Secondly, our study was based on the arterial phase of abdominal CT-scan performed after manual injection of iodinated contrast medium. The images obtained by reformations, MIP and 3-D reconstructions seemed of lower quality compared to that of a "classical" abdominal CT-angiography. This is true in particular for the end portions of the branches of celiac trunk as well as for small caliber arteries such as the stomachic coronary artery. However, the quality of the images was appropriate for a sufficient study of proximal AVs of the celiac trunk.

In our series, the average age was 45.9 years with extremes of 18 and 80 years. This result was comparable to that of Ugurel's [8] study of the Turkish population in 2010. It reported an average age of 49 years with extremes of 10 and 85 years. In contrast, in the anatomical series of Ferrari in Italy, the average age was $60.3 \pm 14.6$ years $[9]$. 
The frequency of AVs in relation to celiac trunk branching was not far from the values found in the literature. Celiac trunk trifurcation (Type I according to Dilli) accounted for $80 \%$ of our patients. The remaining $20 \%$ had at least one AV. Anatomical variant accounted for $21 \%$ in the Ugurel series in Turkey and 38.3\% in Mburu in Kenya. In contrast, Garima in India and Lezzi in Italy reported higher prevalences; $72 \%$ and $79.6 \%$ respectively. Thus the prevalence of AVs of celiac trunk is very variable according to the populations surveyed. Such a difference could depend on genetic characteristics, and the exact definition of the criteria for analysis, and the degree of resolution of the images, and thus the exploration technique. Among patients with AVs, almost half had 2 variants.

AVs with celiac trunk bifurcation were observed in $8.8 \%$ of cases. Chitra and petrella [10] [11] reported inferior results; respectively $6 \%$ and $5.6 \%$. On the other hand a prevalence of $17 \%$ was even observed by Mburu whereas Tiwari noted 2\% [12]. Our series observed two types of bifurcation of the celiac trunk. Hepato-splenic trunk is with $7.5 \%$ and the gastro-splenic trunk with $1.3 \%$. Equivalent proportionality was reported in the Mburu series where hepato-splenic and gastro-splenic trunks accounted for $8 \%$ and $3 \%$, respectively. On the other hand, in the Ugurel and Surucu series [13], the bifurcation of celiac trunk with gastro-splenic artery was the most frequent type with $4.3 \%$ versus $4 \%$ for hepato-splenic trunk. Hepato-gastric bifurcation was not observed in our series. However, this type of bifurcation was reported in a proportion of $0.6 \%$ in Surucu series.

In our series, celiac trunk gave collateral branches in $5.6 \%$ of cases. While Ugurel and Prakash [14] did not describe them in their studies, Chitra reported a prevalence of $54.0 \%$. According to the literature, lower right diaphragmatic artery had a prevalence of between $4 \%$ and $8 \%$ in the general population. In our series, it was $1.9 \%$ and was one of the most common celiac trunk side branches. Mburu and Tiwari had found higher frequencies, with respectively $4.9 \%$ and $8 \%$. In addition, this prevalence was very high according to an American series published by Wadwa with $23 \%$ for right inferior diaphragmatic artery and $20 \%$ for left inferior diaphragmatic artery.

Common celiac and mesenteric trunk occurred in 3.1\% in our series instead of the $1.1 \%$ frequently encountered according to the literature. It should not be misunderstood in the preoperative assessment of the organs of the upper mesocolic stage.

Quadrifurcation of the terminal branches of celiac trunk accounted for 1.2\% of the cases in this study. Marjeta [15] had a higher prevalence of 5.2\%. In our series, the fourth branch consisted of either gastro-duodenal artery or right or left hepatic artery respectively in $0.6 \%$ of cases. While in the Marjeta series, the fourth branch of the celiac trunk was frequently constituted by dorsal pancreatic artery with $2.2 \%$. In the same series, right inferior diaphragmatic artery, or middle colonic artery or accessory pancreatic artery accounted for $0.8 \%$.

Three anatomical features were found in a patient with a left hepatic artery's 
Table 3. Comparison of studies by type of division of celiac trunk.

\begin{tabular}{ccccccc}
\hline Auteurs & Pop & $\begin{array}{c}\text { Trifurcation } \\
\%\end{array}$ & $\begin{array}{c}\text { Bifurcation } \\
\%\end{array}$ & $\begin{array}{c}\text { Collateral } \\
\%\end{array}$ & $\begin{array}{c}\text { Absent } \\
\%\end{array}$ & Nbre \\
\hline Ugurel & Turquie & 89.0 & 8.0 & ---- & 1.0 & 100 \\
Mburu & Kenyan & 61.8 & 17.9 & 20.3 & ---- & 123 \\
Chitra & Inde & 40.0 & 6.0 & 54.0 & ---- & 50 \\
Tiwari & Inde & 84.0 & 2.0 & 14.0 & ---- & 50 \\
Prakash & Inde & 86.0 & 10.0 & ---- & 4.0 & 50 \\
Silveira & Brésil & 85.7 & 9.5 & 4.8 & ---- & 21 \\
Petrella & Brésil & 82.0 & 5.6 & 10.1 & 2.3 & 89 \\
Notre étude & BF & 80.0 & 8.8 & 5.6 & 1.2 & 160 \\
\hline
\end{tabular}

Captions: Nbre: Nombre, Pop: Population, BF: Burkina Faso.

collateral, two right hepatic arteries and a Buhler "pseudo-arch" stretched between celiac trunk and inferior mesenteric artery. We are not aware of an earlier publication of such an association.

Table 3, brings together elements of comparison of AVs related to the mode of division of celiac trunk between our study and seven others.

\section{Conclusion}

Anatomical variants related to celiac trunk branching, are as frequent in our study as in the literature. However, the prevalence of common celiac and mesenteric trunk, was higher than previously accepted values. Three particular anatomical features were found in a patient with a left collateral hepatic artery, two right hepatic arteries and a Buhler "pseudo-arch" stretched between celiac trunk and inferior mesenteric artery. Interpretation of any contrast-enhanced abdominal CT-scan as part of a preoperative assessment is an opportunity to screen anatomical variants of celiac trunk but also of the superior mesenteric artery.

\section{Funding}

This study was not funded.

\section{Conflicts of Interest}

The authors declare that they have no conflict of interest.

\section{References}

[1] White, R.D., Weir-McCall, J.R., Sullivan, C.M., Mustafa, S.A.R., et al. (2015) The Celiac Axis Revisited: Anatomic Variants, Pathologic Features, and Implications for Modern Endovascular Management. Vascular/ Interventional Radiology, 35, 879-898. https://doi.org/10.1148/rg.2015140243

[2] Carlson, B.M. (2013) Human Embryology and Developmental Biology. 5th Edition, Elsevier/Saunders, Philadelphia.

[3] Dillenseger, J.P. (2011) Atlas d'anatomie générale et radiologique. Elsevier Masson, London, CH4, 157-169. 
[4] Ambica, W. and Sandeep, S. (2011) A Composite Study of Celiac Trunk in 30 Adult Human Cadavers-Its Clinical Implications. Global Journal of Medical Research, 11, 35-38.

[5] Mburu, K., Alexander, O.J., Hassan, S. and Bernard, N. (2010) Variations in the Branching Pattern of the Celiac Trunk in a Kenyan Population. International Journal of Morphology, 28, 199-204. https://doi.org/10.4067/S0717-95022010000100028

[6] Abdullahi, D.Z., Jibrin, D.U., Abubakar, B. and Aziz, A.T. (2010) Accessory Right Hepatic Artery Originating from the Superior Mesenteric Artery: Report on Three Cadaveric Cases from Sokoto, North-Western Nigeria and Review of Literature. Orient Journal of Medicine, 22.

[7] Manyama, et al. (2013) A Case of Celiac Mesenteric Trunk in a Tanzanian Man. BMC Research Notes, 6, 341. https://doi.org/10.1186/1756-0500-6-341

[8] Ugurel, M.S., Battal, B., Bozlar, U., et al. (2010) Anatomical Variations of Hepatic Arterial System, Celiac Trunk and Renal Arteries: An Analysis with Multi-Detector CT Angiography. The British Journal of Radiology, 83, 668-673. https://doi.org/10.1259/bjr/21236482

[9] Ferrari, R., De Cecco, C.N., Laghi, A., et al. (2007) Anatomical Variations of the Celiac Trunk and the Mesenteric Arteries Evaluated with 64-Row CT Angiography. La Radiologia Medica, 112, 988-998. https://doi.org/10.1007/s11547-007-0200-2

[10] Chitra, R. (2010) Clinically Relevant Variations of the Celiac Trunk. Singapore Medical Journal, 51, 216-219.

[11] Petrella, S., Rodrigues, C.F.S., Sgrott, E.A., Fernandez, G.J.M., Marques, S.R. and Prates, J.C. (2006) Origin of Inferior Phrenic Arteries in the Celiac Trunk. International Journal of Morphology, 24, 275-278. https://doi.org/10.4067/S0717-95022006000300024

[12] Tiwari, S. and Jeyanthi, K. (2012) Study of Origin of Inferior Phrenic Arteries from the Celiac Trunk. Anatomica Karnataka, 6, 38-41.

[13] Surucu, H.S., Oto, A. and Gokoglu, A. (2010) Anatomical Variations of Hepatic Arterial System, Celiac Trunk and Renal Arteries: An Analysis with Multi-Detector CT Angiography. The British Journal of Radiology, 83, 68-73.

[14] Prakash, T.R., Mokhasi, V., Geethanjali, B.S., et al. (2012) Celiac Trunk and Its Branches: Anatomical Variations and Clinical Implications. Singapore Medical Journal, 53, 329-331.

[15] Tanka, M. and Abazaj, E. (2015) Anatomical Variations of Celiac Trunk Anatomy and Their Clinical Importance. International Journal of Science and Research, 4, 12-14. https://doi.org/10.21275/v4i12.NOV151751 